\title{
Comparative Study Assessing Postoperative Renal Loss Using Two Different Partial Nephrectomy Techniques: Off-Clamp versus Standard On-Clamp Surgery
}

\author{
Shahid Aquil ${ }^{a, c}$ Daniel Olvera-Posada ${ }^{a, d}$ Roshan Navaratnam ${ }^{e}$ \\ David Mikhail $^{a} \quad$ Max A. Levine ${ }^{a}$ Patrick P. Luke ${ }^{a, c}$ Alp Sener ${ }^{a, b, c}$
}

aDivision of Urology, Department of Surgery; 'Multi-Organ Transplant Program, London Health Sciences Center, Western University, London,

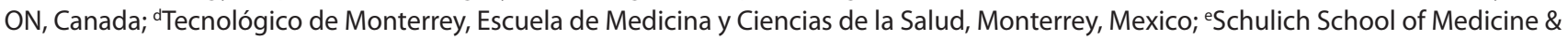

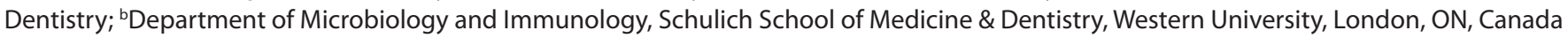

\section{Key Words}

Partial nephrectomy • Off-clamp • Chronic kidney disease • Zero ischemia $\cdot$ Kidney cancer

\begin{abstract}
Objectives: To evaluate a case-matched study comparing postoperative renal function using two surgical techniques: an off-clamp partial nephrectomy (PN) with the aid of the Altrus ${ }^{\oplus}$ device and a standard on-clamp laparoscopic PN. Material and Methods: A total of 36 patients underwent PN. Eighteen had the off-clamp technique and 18 had the standard laparoscopic on-clamp PN. Demographic, clinical, radiological, and perioperative data were collected for analysis. An emphasis on renal function was made by analyzing both the perioperative and follow-up with estimated glomerular filtration rate and MAG3. Results: The median values did not significantly differ for age, Charlson Comorbidity Index, and hospital stay in the off-clamp versus on-clamp PN [62.5 (interquartile range, IQR 11) vs. 60 (IQR 16) years, 4 (IQR 2) vs. 5 (IQR 2) and 5 (IQR 1) vs. 4 (IQR 2) days], respectively. The median diameter of the tumors was 33 (IQR 23) versus 41 (IQR 28) $\mathrm{mm}(\mathrm{p}=0.63)$, with median R.E.N.A.L.
\end{abstract}

\section{KARGER}

Fax +4161306 1234

E-Mail karger@karger.com

www.karger.com
(C) 2020 The Author(s)

Ppen access

This article is licensed under the Creative Commons AttributionNonCommercial-NoDerivatives 4.0 International License (CC BYNC-ND) (http://www.karger.com/Services/OpenAccessLicense) Usage and distribution for commercial purposes as well as any distribution of modified material requires written permission. nephrometry scores of 7 (IQR 2) versus 7 (IQR 2) $(p=0.33)$. There was greater blood loss in the Altrus ${ }^{\circledast}$ ( 375 vs. $200 \mathrm{ml}, \mathrm{p}$ $=0.037)$. The clamp time in the on-clamp group was 30 (IQR 6) minutes (range 22-68 minutes) compared to 0 minutes in the off-clamp group. There was no difference in hemoglobin or creatinine levels between the groups. However, the onclamp group had a significant loss in ipsilateral renal function on the MAG3 scan ( 49 vs. $42 \%, p=0.0001$ ), whereas the off-clamp group had no difference (48 vs. $46 \%, p=0.72$ ). Conclusions: The off-clamp method for PN is a feasible and safe option with better preservation of ipsilateral renal function when compared with on-clamp PN in the treatment of small renal masses.

(c) 2020 The Author(s)

Published by S. Karger AG, Basel

\section{Introduction}

Kidney cancer is one of the 10 most common cancers in United States and Canada, and the majority are classified as small renal masses with a tumor diameter $<4$ 
$\mathrm{cm}[1,2]$. Partial nephrectomy $(\mathrm{PN})$ is the standard extirpative treatment for small renal masses [3-5]. Although, the rate of $\mathrm{PN}$ for T1a renal tumors in population-based studies was reported to be as low as $49.4 \%$, centers of excellence reported the use of PN in approximately $90 \%$ of T1a tumors $[6,7]$. PN is a technically challenging procedure that surgeons with less oncological training or low caseload avoid performing $[8,9]$ and thus community-based practices may be less inclined to perform nephron sparing surgeries compared to academic centers [10]. PN has adequate oncological outcome while maintaining the best renal function possible. The functional benefit of $\mathrm{PN}$ relies on the quantity and quality of nephrons in the remaining kidney.

Ischemia-reperfusion injury (IRI) is considered one of the main causes of renal damage following PN. IRI involves ischemic injury secondary to vascular clamping (warm or cold ischemia) and organ preservation as well as reperfusion injury secondary to the generation of reactive oxygen species and further inflammation. The warm ischemia time (WIT) is one surgically modifiable factor that has been shown to affect postoperative renal function [11]. Contemporary viewpoints on the impact of warm ischemia are controversial, with some morphometric studies not revealing a substantial parenchymal atrophy after warm ischemia [5], but it seems that patients with preoperative chronic kidney disease (CKD) may benefit from avoiding renal ischemia during tumor excision $[12,13]$.

Several technological innovations have been developed to increase the feasibility of performing PN based on procedure-specific surgical tenets: reducing ischemic injury, ensuring negative oncological margins, delicate parenchymal reconstruction, and diminished postoperative complications [14]. Some recent novel approaches include the use of microwave tissue coagulator, electromagnetic thermal surgery systems, thulium laser, and hydro-dissection, which have been described in the literature with promising results, including a recent one by our group using a novel thermal tissue sealant device which enabled off-clamp PN with excellent renal functional outcomes [15-19]. Given the excellent results obtained from animal studies, we wanted to ascertain if these findings would also hold true in human trials.

The objective of the present study was to compare the impact on renal function recovery in two surgical techniques in performing PN. We performed a matched pair analysis of T1 tumors comparing a group of patients treated with an off-clamp PN using the aid of a novel thermal tissue fusion system (Altrus ${ }^{\circledR}$ device) to patients who underwent standard laparoscopic on-clamp PN in our academic center.

\section{Materials and Methods}

Following ethics review board approval (REB\#105811), data was collected on all consecutive patients who underwent PN using one of the following techniques: 1) off-clamp PN using the Altrus ${ }^{\circledR}$ device (10 mm hand piece; ConMed, Utica, NY) and 2) on-clamp laparoscopic PN. A total of 18 cases had each approach during the same year period. All patients had a history and physical examination, biochemical analyses, oncological staging studies, and a preoperative ${ }^{99 \mathrm{~m}} \mathrm{Tc}-\mathrm{MAG} 3$ renogram to assess split renal function. Patients underwent an abdominal CT scan with multiplanar reconstruction that allowed a detailed anatomical description of the renal mass. R.E.N.A.L. nephrometry scores were used to classify the complexity of the renal lesions [20,21].

Prospectively measured variables included age, gender, body mass index, Charlson Comorbidity Index (CCI), estimated glomerular filtration rate (eGFR), solitary kidney status, American Society of Anesthesiologist class risk and use of chronic anticoagulation/antiplatelet drugs. Intraoperative features (surgical approach, operative time, blood loss, opening of the collecting system, and need for hilar clamping), pre- and post-operative hemoglobin and creatinine levels, pathological diagnosis (histology and margin status), and nuclear renogram data were collected. Postoperative complications were graded using the Clavien-Dindo system [22]. eGFR was calculated using the CKD-EPI formula [23]. CKD was defined in accordance with the Kidney Disease Improving Global Outcomes clinical practice guidelines [24].

One of 2 surgeons (A.S. or P.L.) performed each case. Prior to starting the procedure, a ureteral catheter was placed in the affected side for retrograde injection of methylene blue in order to assess intraoperative urinary leaks. The PN was carried out using either a retroperitoneal approach through a flank incision or in a transperitoneal laparoscopic approach. In all cases, Gerota's fascia was opened for tumor exposure but the perinephric fat surrounding the tumor was left in place. The renal hilum was dissected and main vessels isolated with elastic vessel loops in case clamping was required, and electrocautery was used to delineate a margin around the tumor with the assistance of intraoperative ultrasound location of the mass.

In the Altrus ${ }^{\circledR}$ group, electrocautery was used to perforate the renal parenchyma to a depth of $4 \mathrm{~mm}$ at $5 \mathrm{~mm}$ intervals along the previously delineated tumor margin in order to allow the thermal fusion system device tips to enter the renal parenchyma without tearing. The renal mass was resected using the Altrus ${ }^{\circledR}$ device, taking care to only make gradual progression when taking the subsequent bite. The Altrus ${ }^{\circledR}$ device is a hand held surgical instrument that incorporates thermal energy and pressure to seal and transect tissue with a single device fire. Rarely, larger bleeding vessels were over-sewn with 5-0 PDS as encountered. A double-layer renorrhaphy was performed using 2-0 PDS whipstitch over cellulose bolsters keeping the closure tight with metal clips. A 19Fr Blake drain was placed in the paranephric space in all cases.

In the standard on-clamp group, renal arteries and veins were clamped, and laparoscopic scissors were used to resect the tumor. Surgical bed vessels were clipped or coagulated with bipolar cau- 
Table 1. Comparison of preoperative clinical and radiological characteristics between the analyzed groups

\begin{tabular}{lccc}
\hline & Off-clamp PN $(\mathrm{n}=18)$ & On-clamp PN $(\mathrm{n}=18)$ \\
\hline Male, $\mathrm{n}(\%)$ & $11(61)$ & $7(38.9)$ & 0.32 \\
Median age, years & $63(11)$ & $60(16)$ & $28.1(8.4)$ \\
Body mass index $\left(\mathrm{kg} / \mathrm{m}^{2}\right)$ & $31.7(9.8)$ & $8(44)$ & 0.62 \\
Right sided small renal masses & $7(39)$ & $5(2)$ & 1 \\
CCI & $4(2)$ & $0(0)$ & 0.07 \\
Solitary kidney, $\mathrm{n}(\%)$ & $4(22)$ & $6 / 8 / 4(34 / 39 / 22)$ \\
Location upper/middle/lower, n $(\%)$ & $6 / 4 / 8(33 / 22 / 44)$ & $41(28)$ & $7(2)$ \\
Largest diameter, mm & $33(23)$ & $49 \%(9)$ & 0.03 \\
Median R.E.N.A.L. score & $7(2)$ & $144(20)$ & 0.35 \\
Split renal function of affected side & $48 \%(10)$ & $71.56(29)$ & 0.63 \\
Preoperative hemoglobin, g/l & $145(22)$ & $98.4(44)$ \\
Preoperative creatinine, $\mu$ mol/l & $84(44)$ & 0.33 \\
Preoperative eGFR, ml/min & $97.5(45)$ & 0.41 \\
\hline
\end{tabular}

Values expressed are medians (IQR) unless otherwise indicated or percentage.

tery. The renal parenchyma was approximated using double-layer renorrhaphy using 2-0 PDS whipstitch over cellulose bolsters keeping the closure tight with metal clips and tightened as previously described [26]. Hemostatic agents were used as needed.

Prior to reconstruction, all patients had retrograde methylene blue injection that allowed recognition of collecting system defects for appropriate closure using 2-0 or 3-0 PDS. A 19Fr Blake drain was placed in the paranephric space in all cases. Postoperative evaluation in both groups included serial blood tests in hospital followed by MAG3 renogram 8 weeks after hospital discharge in order to evaluate changes in split renal function.

Postoperative surveillance followed the Canadian Urological Association guidelines for renal cell carcinoma (RCC) [25]. Clinical, perioperative, radiological, and pathological information was recorded. Pre- and post-operative characteristics were compared between the groups using the Chi-square test/Fisher's exact test and Mann-Whitney U test. A comparison between pre- and postoperative renal function, hemoglobin, and split renal function was performed using the Student's t-test. All p-values were two-sided and $\mathrm{p}<0.05$ was considered statistically significant. Data are presented as medians and interquartile range (IQR). Statistical analysis was performed using IBM SPSS Statistics for Windows, Version 20.0 (Armonk, NY, IBM Corp).

\section{Results}

A total of 36 patients underwent PN; 18 patients had off-clamp PN (16 through an open approach and 2 laparoscopically), while 18 patients had laparoscopic PN with the on-clamp technique. Table 1 shows preoperative characteristics of patients in each group. Patients in both groups had a significant but similar comorbidity burden, reflected by the median CCI of 4 (IQR 2) versus 5 (IQR $2)(p=0.062)$ in the off-clamp and on-clamp groups, re- spectively. Four patients underwent PN in a solitary kidney using the off-clamp technique. Median length of stay was 5 (IQR 1) days in the off-clamp group and 4 (IQR 2) days in the on-clamp group $(\mathrm{p}=0.56)$.

Preoperative variables were similar between both groups. Renal masses had a similar distribution in renal topography with a comparable R.E.N.A.L. score, and there were no differences in $\mathrm{T}$ stage classification. Table 1 shows the comparison of preoperative data between groups.

Off-clamp surgeries had a median operative time of 192 minutes, compared to 222 minutes in the on-clamp group $(\mathrm{p}=0.14)$. As expected, there was a slight increase in the estimated blood loss observed in the off-clamp PN group ( 375 vs. $200 \mathrm{ml}, \mathrm{p}=0.037$ ) and this was reflected by the need of perioperative transfusion in 4 patients. One patient had a history of hepatitis $\mathrm{C}$ and low platelets and the other 3 had very vascular tumors $(\mathrm{p}=0.001)$. Two Clavien 3 a complications occurred in the off-clamp PN group including a solitary kidney patient with stage $3 \mathrm{CKD}$ that required temporary hemodialysis (for 3 weeks), and another requiring the placement of a double $\mathrm{J}$ stent due to clot colic and obstruction. Complications in the on-clamp PN group included a patient with aspiration pneumonitis requiring ICU management (Clavien $4 \mathrm{a}$ ), a patient with postoperative urine leak (Clavien 2), a patient with a perinephric abscess requiring a percutaneous drain (Clavien 3a), and a patient suffering a postoperative bleed treated with splenectomy and ICU (Clavien 4a). There were no differences in the rate of 30-day complications between the 2 groups $(\mathrm{p}=0.47)$. 
Table 2. Comparison of intra-operative (surgical) and post-operative (clinical) characteristics between the analyzed groups

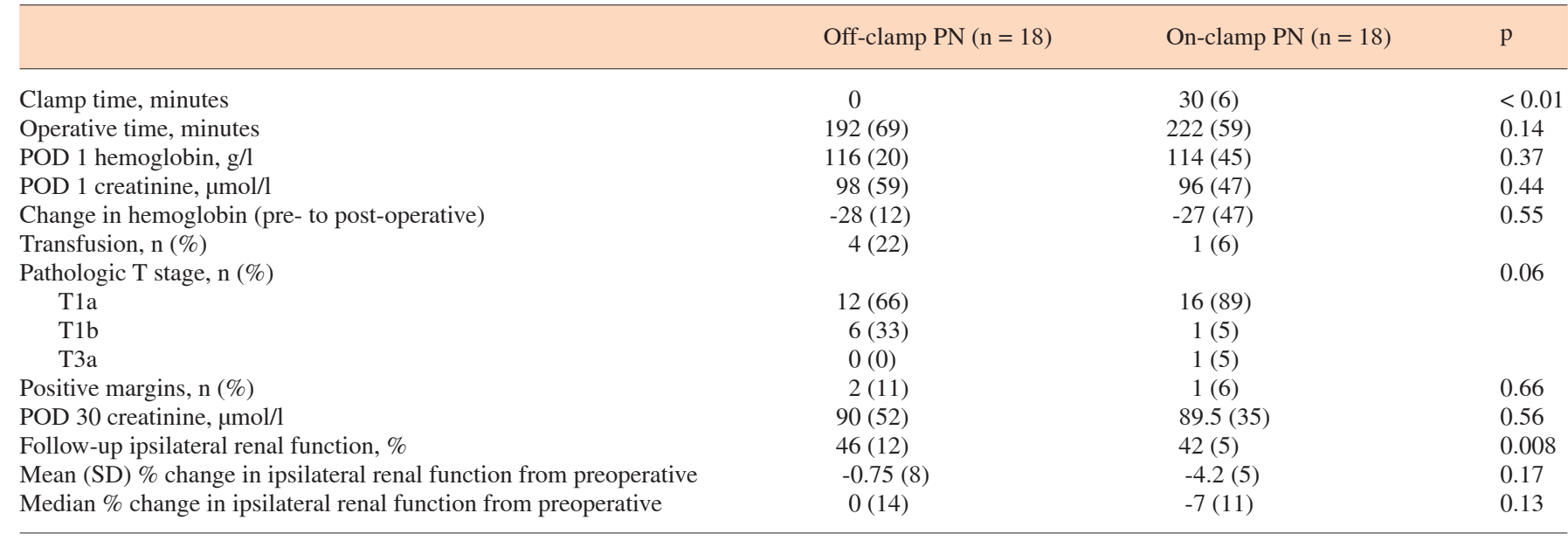

Values expressed are medians (IQR) unless otherwise indicated or percentage; POD = Postoperative day.

Table 3. Histological diagnosis of renal masses in both groups

\begin{tabular}{lcl}
\hline & Off-clamp PN & On-clamp PN \\
\hline Clear cell RCC & 10 & 9 \\
Papillary RCC & 6 & 4 \\
Chromophobe RCC & 1 & 1 \\
Oncocytoma & 1 & 3 \\
Angiomyolipoma & 0 & 1 \\
\hline
\end{tabular}

Postoperative evaluation showed no differences in hemoglobin and serum creatinine levels (table 2). While the preoperative renal function of the affected side containing the tumor was similar between both groups, postoperative follow-up renograms revealed a difference in on-clamp PN patients who demonstrated a significant renal function loss after surgery according to pre- and postoperation MAG3 renograms (49 vs. 42\%, p = 0.001), whereas the off-clamp approach did not significantly affect the median values for split renal function (48 vs. $46 \%, \mathrm{p}=0.72$ ).

Pathology confirmed malignancy in 31 of $36(86 \%)$ cases, with a similar distribution of histological subtypes between groups, as demonstrated in table 3. The proportion of patients with positive margins did not significantly differ between groups and there has not been any local recurrence in any of these patients to date.

Comparative Study: Off-Clamp vs.

On-Clamp Surgery

\section{Discussion}

Currently, PN remains the preferred treatment for small renal masses in patients considering curative intervention. Our recent findings in a series of animal experiments revealed that off-clamp PN is a safe and feasible alternative to on-clamp PN with the added benefit of providing greater renal protection by minimizing the effects of renal IRI on the ipsilateral renal moiety [19]. The current data support that off-clamp PN using a novel thermal energy device to simultaneously dissect the mass and coagulate surrounding vessels, thus eliminating the need for hilar clamping during the procedure is not only safe and feasible, but also produces improved results compared to on-clamp PN.

Renal vascular clamping is a potentially modifiable surgical factor that may play a role in improving patient outcomes by reducing renal ischemic injury. The overall impact of the utility of performing zero-ischemia PN in patients without preexisting CKD has been debated in recent studies. Salevitz et al. [26] provided retrospective evidence that on-clamp PN is a safe surgical technique with acceptable long-term renal function outcomes in patients with 2 kidneys, assessed by MAG3 renograms and eGFR. Lane et al. [27] suggested that the survival benefit of renal function preservation in $\mathrm{PN}$ was conferred mainly to patients with preoperative CKD. However, a recently systematic review recommended that off-clamp 
PN is particularly useful in patients with a decreased baseline renal function [28].

Our initial results demonstrate that the off-clamp PN is a feasible technique with minimal complications even for patients with a high comorbidity burden or a solitary kidney. Furthermore, these results also suggest that the off-clamp method may offer better renal function preservation of the affected unit. Although there was no significant change in the serum creatinine levels following surgery, only the cases treated with the Altrus ${ }^{\circledR}$ device showed $95-100 \%$ preserved split renal function in the majority of cases on MAG3 renogram assessment. With regards to preservation of the ipsilateral renal function, the off-clamp method appears to be superior to the onclamp method by eliminating WIT altogether. This is consistent with our previous study showing that incremental increases in WIT lead to impaired preservation of the ipsilateral renal function [11]. This study has once again demonstrated the positive impact zero WIT has on preservation of renal function after PN. In this study, we accomplished excision of tumors with the Altrus ${ }^{\circledR}$ device, but conceivably any device for tumor excision could lead to similar preservation outcomes. The benefit, in our opinion, of the Altrus ${ }^{\circledR}$ device is the ability to minimize blood loss during excision that may otherwise occur offclamp without such a device.

The Altrus ${ }^{\circledR}$ device has been extensively used for abdominal procedures, but its use in PN has never been evaluated. We found that the parallel closure of the jaws is particularly helpful for renal parenchymal transection and hemostasis, although large vessels require stitch placement to ensure adequate hemostasis. An adequate level of comfort accompanied the use of this device while performing the PN, but it is important to clarify that the renal hilum was always isolated in all cases before resection in case of profound bleeding requiring hilar clamping.

One of the main strengths of this study is the prospective collection of the data and the detailed evaluation of renal function by serum creatinine, eGFR, and MAG3 renograms. Limitations of the present study include the small number of patients, which makes the interpretation of the statistical analysis difficult. Also, there was heterogeneity in surgical techniques, potentially minimizing internal validity. All of the on-clamp PN were carried out in a laparoscopic fashion; whereas the off-clamp procedures were majority open with only 2 done laparoscopically. Despite these technical differences, the overall clinical findings between the 2 groups with respect to postoperative clinical course and outcomes were similar. The only major difference was the greater deleterious effect of on-clamp PN on renal function. However, an attempt at minimizing heterogeneity was sought by having only 2 surgeons perform both techniques for all patients.

\section{Conclusions}

Our initial results indicate that off-clamp PN with the aid of the Altrus ${ }^{\circledR}$ device is feasible with minimal complication risks and prevents deterioration of the renal function, especially in patients with comorbidities contributing to $\mathrm{CKD}$. These results provide reassurance that energy devices could be useful in facilitating an off-clamp, nephron-sparing approach for the treatment of small renal masses. However, a multicenter trial is needed to further expand upon our findings.

\section{References}

1 American Cancer Society: Kidney cancer. Accessed October 2015 from: http://www. cancer.org/cancer/kidneycancer/index.

2 Canadian Cancer Society: Kidney cancer statistics. Accessed October 2015 from: http://www.cancer.ca/en/cancer-information/ cancer-type/kidney/statistics/.

-3 Campbell SC, Novick AC, Belldegrun A, Blute ML, Chow GK, Derweesh IH, Faraday MM, Kaouk JH, Leveillee RJ, Matin SF, Russo P, Uzzo RG: Guideline for management of the clinical T1 renal mass. J Urol 2009;182:1271-1279.
-4 Ljungberg B, Bensalah K, Canfield S, Dabestani S, Hofmann F, Hora M, Kuczyk MA, Lam T, Marconi L, Merseburger AS, Mulders P, Powles T, Staehler M, Volpe A, Bex A: EAU guidelines on renal cell carcinoma: 2014 update. Eur Urol 2015;67:913-924.

5 Campbell S, Demirjian S, Zhang Z: Renal function after renal cancer surgery. AUA Update Series. Volumen 34, Lesson 23, 2015.

-6 Schiffmann J, Bianchi M, Sun M, Becker A: Trends in surgical management of T1 renal cell carcinoma. Curr Urol Rep 2014;15:383.
7 Thompson RH, Kaag M, Vickers A, Kundu S, Bernstein M, Lowrance W, Galvin D, Dalbagni G, Touijer K, Russo P: Contemporary use of partial nephrectomy at a tertiary care center in the United States. J Urol 2009; 181: 993-997.

-8 Breau RH, Crispen PL, Jenkins SM, Blute ML, Leibovich BC: Treatment of patients with small renal masses: a survey of the American Urological Association. J Urol 2011;185:407413. 
$>9$ Poon SA, Silberstein JL, Chen LY, Ehdaie B, Kim PH, Russo P: Trends in partial and radical nephrectomy: an analysis of case logs from certifying urologists. J Urol 2013;190: 464-469.

10 Lane BR, Golan S, Eggener S, Tobert CM, Kahnoski RJ, Kutikov A, Smaldone M, Whelan CM, Shalhav A, Uzzo RG: Differential use of partial nephrectomy for intermediate and high complexity tumors may explain variability in reported utilization rates. J Urol 2013;189:2047-2053.

-11 Chan E, Boyle SL, Campbell J, Luke PP Ipsilateral renal function preservation following minimally invasive partial nephrectomy: the effect of tumour characteristics and warm ischemic time. Can Urol Assoc J 2017;11:344-349.

12 Campbell J, Chan G, Luke PP: Early clamp release during laparoscopic partial nephrectomy: implications for preservation of renal function. Can Urol Assoc J 2017;11:E261265.

13 Deng W, Liu X, Hu J, Chen L, Fu B: Offclamp partial nephrectomy has a positive impact on short- and long-term renal function: a systematic review and meta-analysis. BMC Nephrol 2018;19:188.

$>14$ Gill I: Towards the ideal partial nephrectomy. Eur Urol 2012;62:1009-1010.

-15 Kawai N, Yasui T, Umemoto Y, Kubota Y, Mizuno K, Okada A, Ando R, Tozawa K, Hayashi Y, Kohri K: Laparoendoscopic single-site partial nephrectomy without hilar clamping using a microwave tissue coagulator. J Endourol 2014;28:184-190.
$16 \mathrm{Ou} \mathrm{CH}$, Yang WH, Tsai HW, Lee TJ, Chen SY, Huang SC, Chang YY, Lee GB, Lin $\mathrm{XZ}$ : Partial nephrectomy without renal ischemia using an electromagnetic thermal surgery system in a porcine model. Urology 2013;81:1101-1107.

17 Knudsen BE, Chew BH, Tan AH, Beiko DT, Denstedt JD, Pautler SE: Assessment of hydrodissection, holmium:YAG laser vaporization of renal tissue, and both combined to facilitate laparoscopic partial nephrectomy in porcine model. Urology 2010;75:1209-1212.

18 Thomas AZ, Smyth L, Hennessey D, O'Kelly F, Moran D, Lynch TH: Zero ischemia laparoscopic partial thulium laser nephrectomy. J Endourol 2013;27:1366-1370.

19 Olvera-Posada D, Lin S, Aboalsamh G, Haig A, Lobb I, Grewal J, Saha MN, Sener A: A novel approach to off-clamp partial nephrectomy demonstrates significant improvements in renal injury in an experimental porcine model. Can Urol Assoc J 2017;11:E390-395.

20 Kutikov A, Uzzo RG: The R.E.N.A.L. nephrometry score: a comprehensive standardized system for quantitating renal tumor size, location and depth. J Urol 2009;182:844-853.

21 Simmons MN, Hillyer SP, Lee BH, Lee BH, Fergany AF, Kaouk J, Campbell SC: Diameter-axial-polar nephrometry: integration and optimization of R.E.N.A.L. and centrality index scoring systems. J Urol 2012;188:384390.

22 Dindo D, Demartines N, Clavien PA: Classification of surgical complications: a new proposal with evaluation in a cohort of 6336 patients and results of a survey. Ann Surg 2004;240:205-213.
23 Levey AS, Stevens LA, Schmid CH, Zhang YL, Castro AF 3rd, Feldman HI, Kusek JW, Eggers P, Van Lente F, Greene T, Coresh J: A new equation to estimate glomerular filtration rate. Ann Intern Med 2009;150:604-612.

24 Stevens PE, Levin A: Evaluation and management of chronic kidney disease: synopsis of the kidney disease: improving global outcomes 2012 clinical practice guideline. Ann Intern Med 2013;158:825-830.

-25 Kassouf W, Siemens R, Morash C, Lacombe L, Jewett M, Goldenberg L, Chin J, Chetner M, Wood CG, Tanguay S, Aprikian AG: Follow-up guidelines after radical or partial nephrectomy for localized and locally advanced renal cell carcinoma. Can Urol Assoc J 2009;3:73-76.

26 Salevitz DA, Patton MW, Tyson MD 2nd, Nunez-Nateras R, Ferrigni EN, Andrews PE, Humphreys MR, Castle EP: The impact of ischemia on long-term renal function after partial nephrectomy in the two kidney model. J Endourol 2015;29:474-478.

27 Lane BR, Campbell SC, Demirjian S, Fergany AF: Surgically induced chronic kidney disease may be associated with a lower risk of progression and mortality than medical chronic kidney disease. J Urol 2013;189: 1649-1655.

28 Simone G, Gill IS Mottrie A, Kutikov A, Patard JJ, Alcaraz A, Rogers CG: Indications, techniques, outcomes, and limitations for minimally ischemic and off-clamp partial nephrectomy: a systematic review of the literature. Eur Urol 2015;68:632-640. 